\title{
ERCOT Event on February 26, 2008: Lessons Learned
}

Technical Report NREL/TP-500-43373 July 2008

E. Ela

National Renewable Energy Laboratory

B. Kirby

Oak Ridge National Laboratory

NREL is operated by Midwest Research Institute • Battelle Contract No. DE-AC36-99-G010337

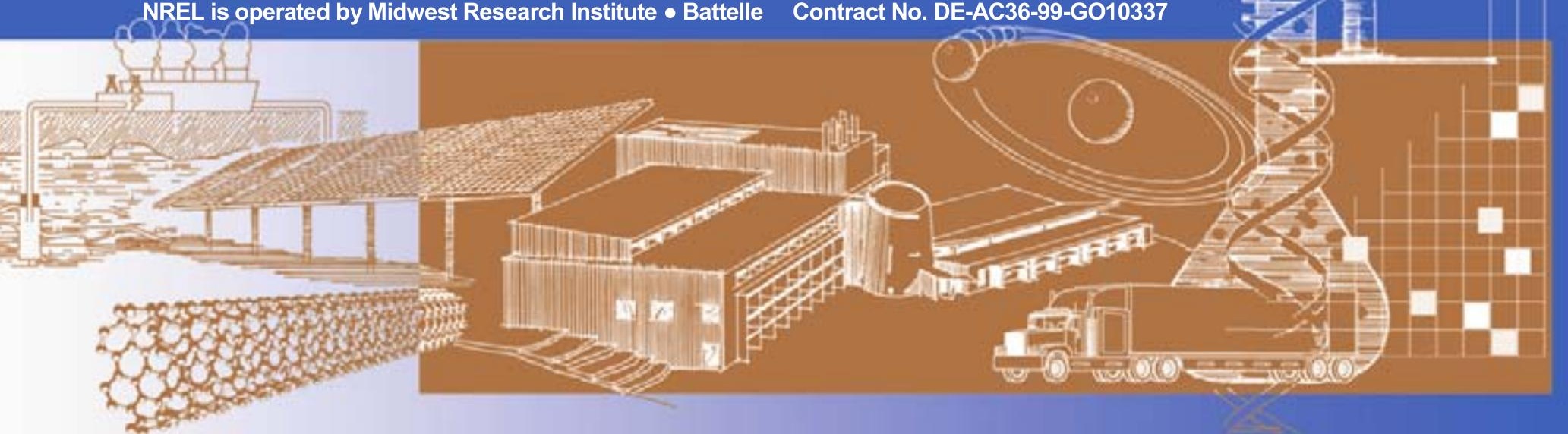




\section{ERCOT Event on February 26, 2008: Lessons Learned}

E. Ela

National Renewable Energy Laboratory

B. Kirby

Oak Ridge National Laboratory

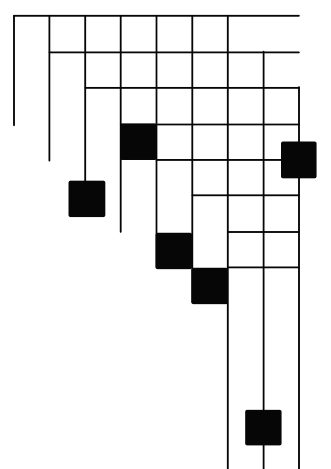

Prepared under Task No. WER8.5001 


\section{NOTICE}

This report was prepared as an account of work sponsored by an agency of the United States government. Neither the United States government nor any agency thereof, nor any of their employees, makes any warranty, express or implied, or assumes any legal liability or responsibility for the accuracy, completeness, or usefulness of any information, apparatus, product, or process disclosed, or represents that its use would not infringe privately owned rights. Reference herein to any specific commercial product, process, or service by trade name, trademark, manufacturer, or otherwise does not necessarily constitute or imply its endorsement, recommendation, or favoring by the United States government or any agency thereof. The views and opinions of authors expressed herein do not necessarily state or reflect those of the United States government or any agency thereof.

Available electronically at http://www.osti.gov/bridge

Available for a processing fee to U.S. Department of Energy and its contractors, in paper, from:

U.S. Department of Energy

Office of Scientific and Technical Information

P.O. Box 62

Oak Ridge, TN 37831-0062

phone: 865.576 .8401

fax: 865.576 .5728

email: mailto:reports@adonis.osti.gov

Available for sale to the public, in paper, from:

U.S. Department of Commerce

National Technical Information Service

5285 Port Royal Road

Springfield, VA 22161

phone: 800.553 .6847

fax: 703.605.6900

email: orders@ntis.fedworld.gov

online ordering: http://www.ntis.gov/ordering.htm 


\section{Introduction/Abstract}

On February 26, 2008, the Electric Reliability Council of Texas (ERCOT) called for an Emergency Electric Curtailment Plan (EECP) at 18:41 due to a worsening imbalance between generation and load which led to a decline in system frequency. The event is of special interest, and was widely reported on in the press, because wind generation played a partial role in the event. Other load-response events, which did not involve wind generation, have not received similar attention.

Three major contributions to this event include a large ramp-down of wind generation which started at 15:00, the unexpected loss of conventional generation, and a quicker than expected evening load ramp-up. Collectively these factors led to ERCOT calling on reserve capacity, including Loads acting as a Resource (LaaR) - large industrial and commercial electricity users who have agreed to allow ERCOT to curtail their electricity supply in exchange for economic compensation - to both increase generation and reduce total demand. With a more accurate generation and demand forecast, ERCOT could have easily scheduled additional generation to be available in advance of the evening load pickup and avoided the need for this emergency response. The event itself lasted less than two hours and no customers lost power involuntarily.

\section{EECP}

The EECP is called on by ERCOT when the amount of available generation is limited. EECP has four steps depending on the criticality of the event. Each of these steps has different procedures based on what actions ERCOT will carry out. Before EECP is called, ERCOT will usually issue an Operating Condition Notice, an Advisory, an Alert, and an Emergency Notice as conditions worsen. These notifications are designed to elicit full, available market response to increase generation supply and maintain reliability.

Once the amount of adjusted reserves is below $2300 \mathrm{MW}$, ERCOT will enter into EECP Step 1. This step allows operators to use the DC ties to import as much power as possible into the ERCOT system and to use out-of-merit generation dispatch to bring on line all available additional generation that can physically respond. Step 2 is entered when reserves fall below $1750 \mathrm{MW}$ and allows the ERCOT operators to call upon all responsive reserves from LaaR, request Block Load Transfers to neighbors, and strongly encourage conservation through media appeals. Step 3 uses 'Emergency Interruptible Load Services' to maintain system frequency at $60 \mathrm{~Hz}$. The EECP Step 4 allows ERCOT system operators to shed firm load in 100-MW blocks if system frequency drops to 59.8 $\mathrm{Hz}$.

The event on February 26 caused an EECP Step 2, where LaaRs were curtailed, but otherwise no load was turned off.

\section{Event Chronology}

- 15:00 - Wind generation output at 2000 MW and begins a 3.5-hour ramp down to $360 \mathrm{MW}$ at 18:30. The down ramp was 2 hours sooner and somewhat faster ( 8 $\mathrm{MW} /$ minute vs. $5 \mathrm{MW} /$ minute) than forecast the day ahead. 
- 17:10 - Evening load ramp begins, increasing $3800 \mathrm{MW}$ in 90 minutes, (42 $\mathrm{MW} /$ minute). The evening load ramp-up began 25 minutes earlier than the shortterm hour-ahead load forecast predicted.

- 17:44 - 150 MW conventional unit trips offline (370-MW capacity).

- 18:00 - Responsive reserves rapidly declining, up-balancing energy bid stack depleted, up-regulation depleted, frequency declining, load increasing at $50 \mathrm{MW} /$ minute.

- 18:24 - Reserves fall below 3000 MW and ERCOT issues an Advisory.

- 18:28 - ERCOT calls on non-spin service to come on-line and requests startup of combustion turbines.

- $\quad$ 18:30 - Frequency declines to $59.94 \mathrm{~Hz}$.

- $\quad 18: 33$ - $328 \mathrm{MW}$ of Responsive (spinning) Reserve deployed automatically because of low frequency $(59.91 \mathrm{~Hz})$.

- 18:41 - Responsive reserves at $1725 \mathrm{MW}$, system frequency at 59.85 Hz: ERCOT declares EECP Step 2.

- 18:49 - ERCOT instructs $1150 \mathrm{MW}$ of LaaRs to reduce consumption.

- ERCOT requested emergency power from SPP. This request was never successfully completed.

- $\quad$ 18:52 - Frequency recovers to $60 \mathrm{~Hz}$.

- 18:56 - Spinning reserve deployment ends.

- 18:59 - LaaR response reaches $1108 \mathrm{MW}$ within 10 minutes (1200 MW within 12 minutes).

- 20:08 - ERCOT ends Step 2 and enters Step 1, LaaR deployment ends and loads allowed to return to service.

- 20:15 - Requested and received 30 MW of emergency power from Mexico.

- 21:40 - EECP terminated.

\section{Load Forecast}

ERCOT uses two main load forecasts when determining unit commitment and dispatch. The first, called the medium-term or 'Day-Ahead' load forecast is used to assure that enough generation is scheduled to be on-line to meet the hour-by-hour demand for the following day. The second, usually referred to as a short-term or real-time load forecast, is used in near real-time to adjust online capacity to meet the changing load demand on a more granular scale (e.g., 5 or 15 minutes). Both forecasts use similar inputs (weather forecast, historical load data, etc.). During the evening of February $26^{\text {th }}$, expected DayAhead demand and scheduled supply (including 1294 MW of scheduled wind) indicated a $1400 \mathrm{MW}$ excess of generation above load. Because of this excess, ERCOT had no reason to procure additional reserve capacity. Figure 1 shows the Day-Ahead load forecast and the actual load for February 26, 2008. The Day-Ahead forecast is well above the actual load, except for the time immediately before and after the 18:41 reliability event. 


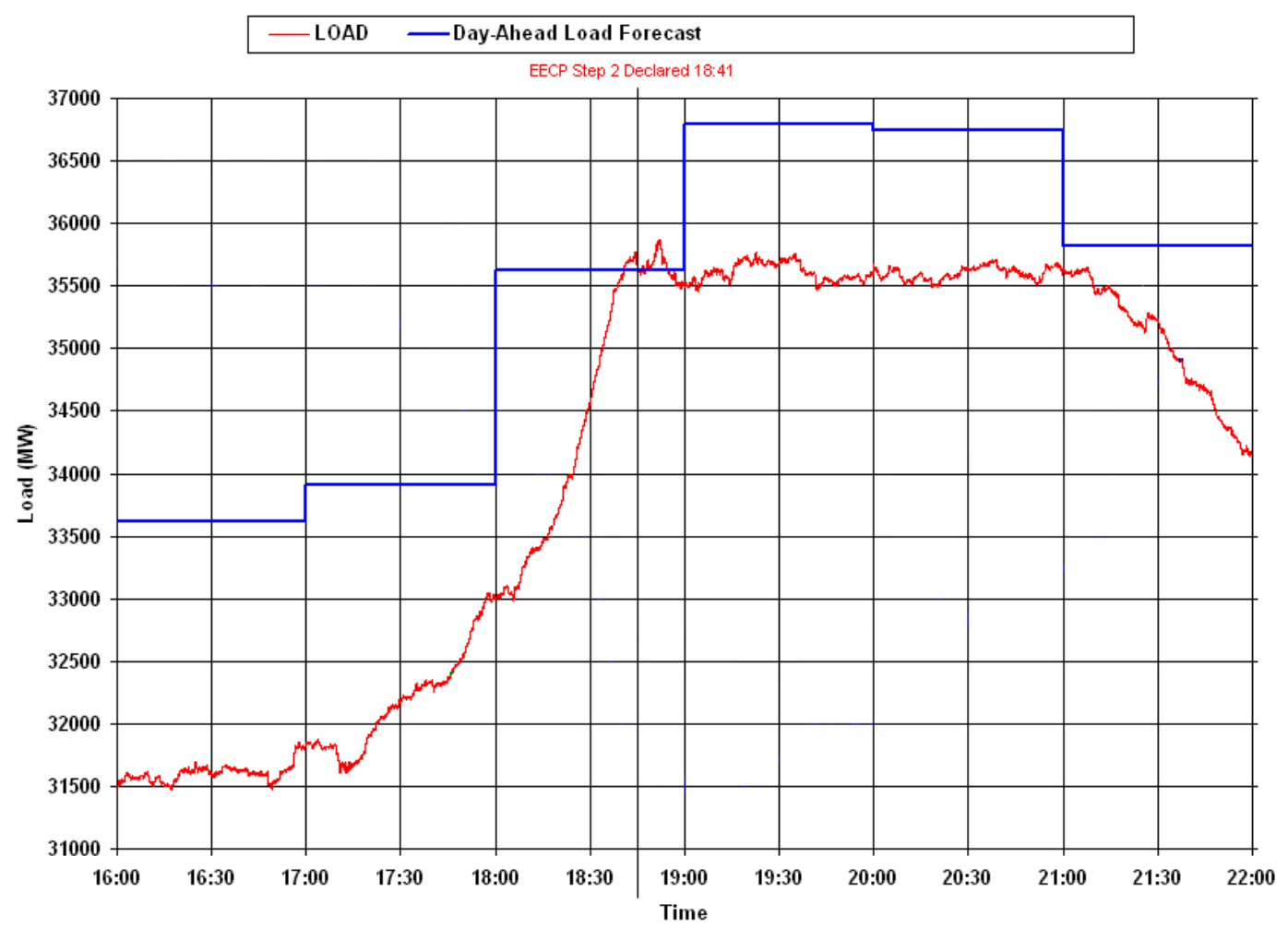

Figure 1. The Day-Ahead forecast exceeded the actual load on February 26 except for the few minutes around the 18:41 reliability event. (Figure adapted from ERCOT Operations Report)

One key observation is the rapid load increase from 18:00 to 18:45; more than 2,500 MW, or about $55 \mathrm{MW} / \mathrm{min}$. This was not an unusual ramp; morning load pickups often exceed $75 \mathrm{MW} / \mathrm{min}$ in ERCOT and winter evening pickups like this one often reach 50$60 \mathrm{MW} / \mathrm{min}$. While the February 26, 2008 load ramp itself was not extremely large, it did differ from the pattern seen the day before (Figure 2). Note that both days are weekdays. 


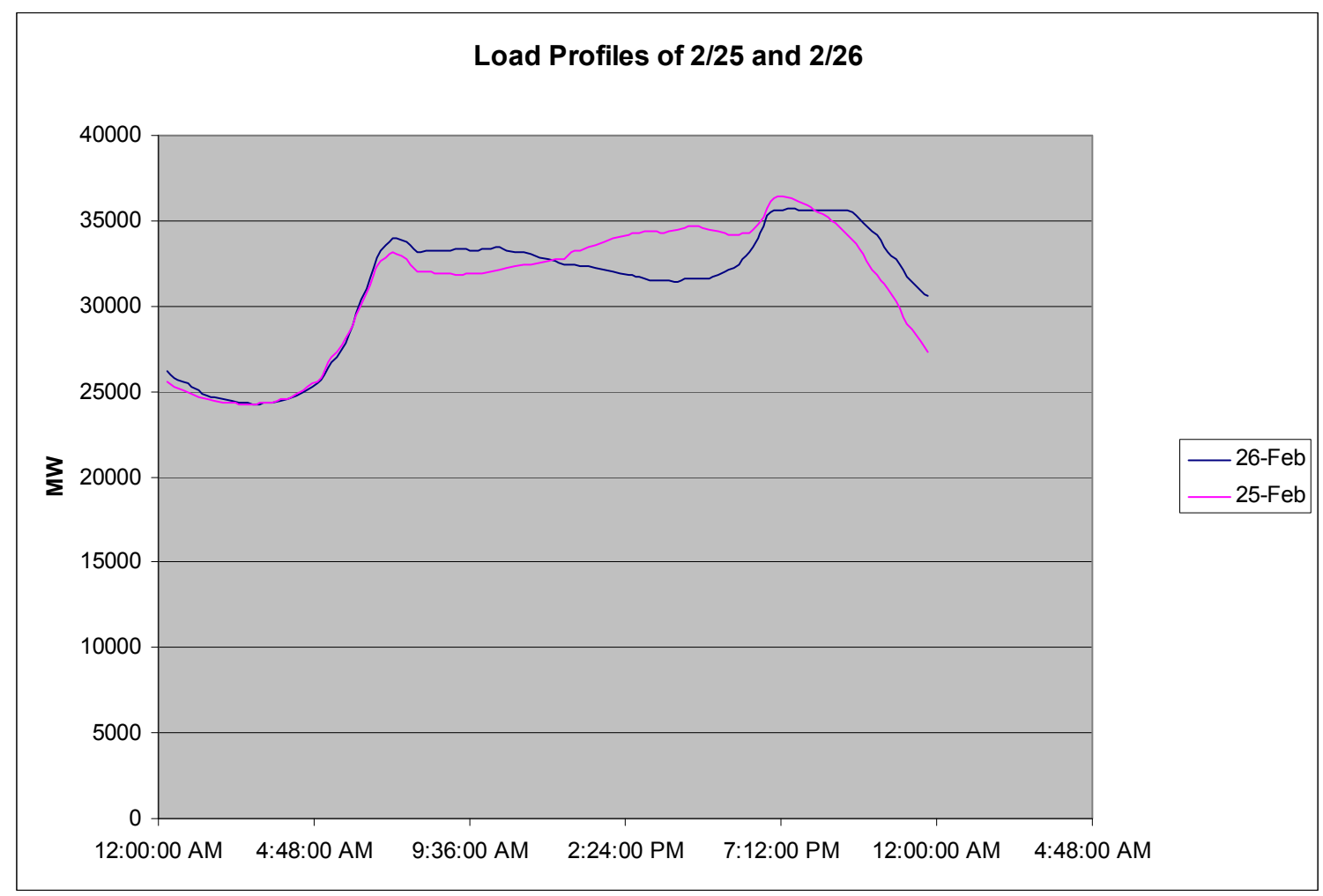

Figure 2. The late afternoon load pattern differed significantly on February 26, 2008 from the pattern seen the day before.

Figure 2 shows that the load profiles after the morning load pickup differ by quite a bit. As stated earlier, historical load data is a key input to the load forecaster. Once the prior day's data is available (i.e., for the short-term load forecast) it is used to predict the upcoming load. Figure 3 shows both days' actual load profiles along with the short-term load forecast (STLF) for the event day. As can be seen, the short-term load forecast performed very well when the event day coincided with the previous day, but did not when the two diverged. This was a major factor in triggering of the EECP as the load ramp occurred prior to the short-term load forecast prediction, more than a $3 \%$ error (more than 1,000 MW) resulting from the influence of the prior day's load profile. The next section discusses wind energy forecasting, which unlike load forecasts, tend not to be correlated from one day to another and therefore rely much less on data from the prior day, and more on the most recent data received for the current day. 


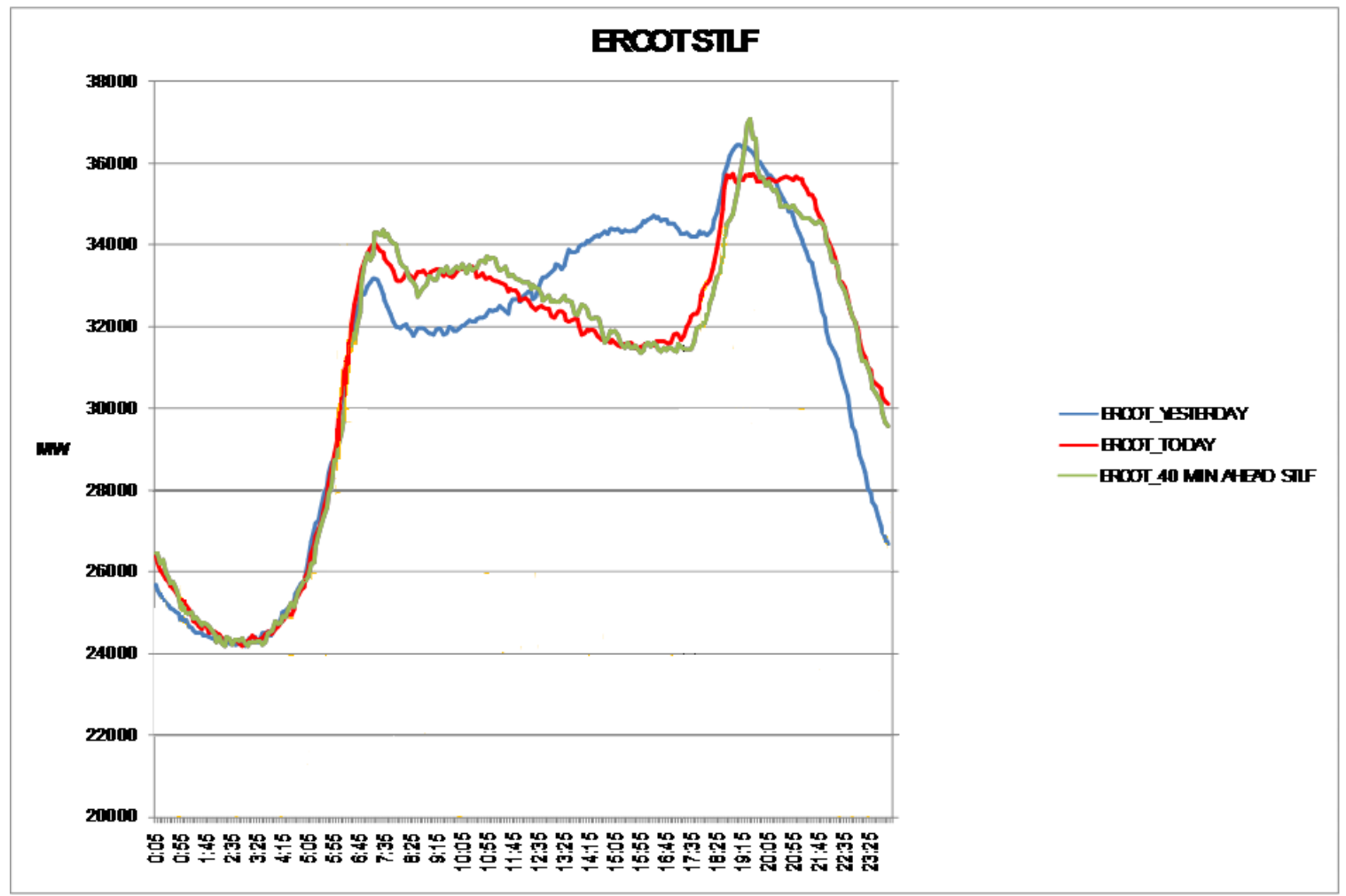

Figure 3. The short term load forecast failed to predict the February 26, 2008 ("Today") load and instead followed the pattern of the previous ("Yesterday") day. (Figure adapted from ERCOT PDCWG presentation on March 11, 2008)

\section{Wind Energy Forecasting}

One portion of the incorrect amount of available capacity given by the Qualified Scheduling Entities (QSE) during this event (although by no means the only one) was the assessment of wind power availability. As has been stated a number of times following this event, the forecast of wind power coming from ERCOT's contracted forecast provider was very accurate in its prediction. Unfortunately, this wind forecast had not yet been integrated into ERCOT's system operations on February 26th. Instead, the scheduling of wind resources was done based on their corresponding QSE's resource schedules that are given to ERCOT both a day ahead and about an hour before the operating hour. While the use of the forecast is an obvious lesson learned and has been anticipated for quite a while at ERCOT, the way by which it is used can be just as important as the forecast itself.

Most scheduling software applications have a built-in sanity check so that resource capabilities are not misrepresented. This might include taking the metered output of generation at the time the application initializes, as well as the response rate of that generator to determine how much actual capacity is possible. For wind generation, one can say it has essentially no response rate since it cannot respond to dispatch orders (wind generators do have some capability of downward response, however). Therefore, the value of the wind generator's capability is assumed based on its generation output during the initialization of scheduling. This is effectively a persistence-based forecast that has 
almost no cost of implementation. This type of assessment works very well for flatter periods, but decreases in effectiveness for larger ramping periods like the one during this event.

Most state-of-the-art short-term wind energy forecasts build upon this idea by taking recent data and using more sophisticated mathematical techniques to produce a forecast of the wind energy. This is very similar to the short-term load forecast, where a major predictor is past behavior. This causes a characteristic error of "delay." The forecast tends to trail reality as it is strongly influenced by a persistence forecast. Alternatively, a DayAhead wind energy forecast may have the correct profile of the wind production, but shifted in time forward or backward. This would also give larger errors when the wind production is moving in fast ramps before or after it was expected. In both instances, it is up to the system operator to prepare for the wind event, and by looking at both the forecast and actual generation data, act appropriately.

Some of the more advanced short-term wind energy forecasts will use offsite observations to get signals about the upcoming ramping behavior. With the ideal scenario of having multiple offsite observations all being a radius of an hour away, an oncoming ramp could be more accurately forecast an hour ahead of time.

Setting aside the algorithms that come up with a wind energy forecast, the forecast itself needs to be presented to the system operators in a way that allows them to prepare for large changes in wind generation. This may include using an appropriate advisory time frame, as well as an assessment of the variability inside a normal forecasting time frame. Since day-ahead unit commitment is an evaluation of the entire day, a full-day wind forecast is usually used in conjunction with a full-day load forecast. During real-time operation, system operators still need to see a few hours ahead, and be able to prepare for large increases and decreases of wind generation since it may be possible that slower start-up units may have to be turned on to accommodate lost generation. It can also give efficient solutions based on the duration of a wind power increase or decrease. For example, let's assume the wind forecast predicted that during the February 26th event, the wind power decreased in hour 18, but by 19:30, the wind generation began to increase to where it had been previously. The system operator in this case would know that it might make more sense to have some quick start units with shorter minimum run times on during this time, rather than to bring up a unit with a long minimum run-time and most likely, a high startup cost.

Figure 4 shows the hour-ahead resource plan for all wind given by the QSEs, the wind forecast from the forecast provider to be used in the future ERCOT nodal system (forecast uses an $80 \%$ exceedance level), and the actual wind generation output. 


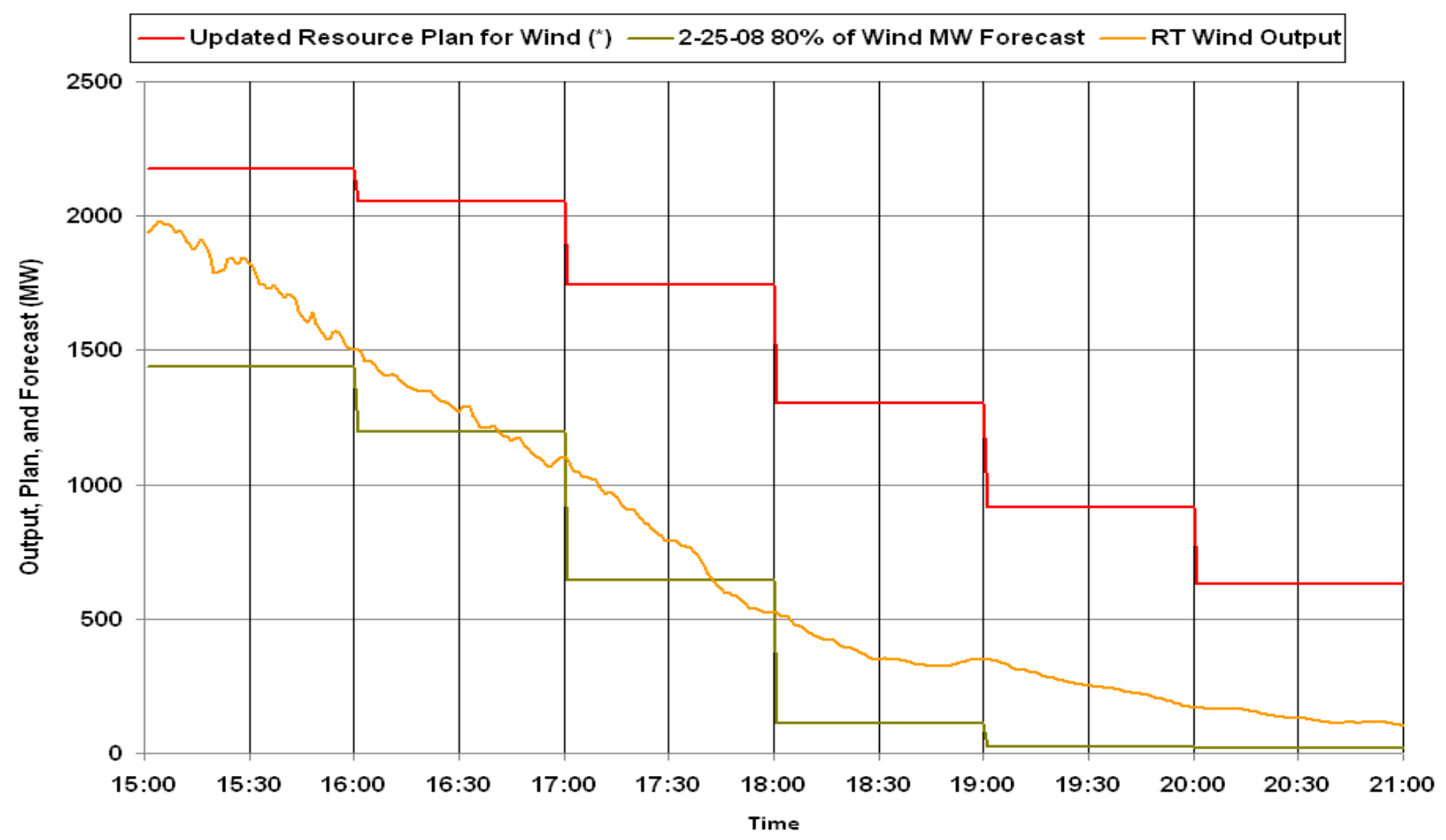

Figure 4. Comparison of wind generation, wind forecast, and wind power resource plans (figure from ERCOT Operations Report, http://www.ercot.com/meetings/ros/keydocs/2008/0313/07. ERCOT OPERATIONS_REPORT_EECP022608_public.doc)

Comparing the forecast and actual data for the 16:00 hour, one would say that the forecast is fairly accurate. However, one could also argue that by using the 16:00 forecast, it is actually close to $300 \mathrm{MW}$ less than the actual production at exactly 16:00. During unit commitment decisions, especially those made day-ahead, system operators are typically not largely worried about the dispatch of the generation as long as there is enough capacity and reserve able to be adjusted when needed in real-time. That being said, this forecast is extremely useful in knowing that commitments should be chosen based on about $1200 \mathrm{MW}$ of wind generation for the 16:00 hour. However, when operators are trying to match generation to load as closely as possible during real-time operation, $300 \mathrm{MW}$ is a pretty big deviation. Especially during faster wind ramping periods, an hourly average sometimes cannot give the entire story of what the wind is doing for that entire time period. To mitigate this situation, there are a few things that system operators can do. First, by requesting shorter time periods for the wind forecast power averages from the forecast provider when solving economic dispatch (e.g., 15 min forecast averages) you can get a more accurate result that more closely aligns with the timeframes for available load forecasts and balancing energy schedules. Second, as discussed before, by updating the forecasts with the most-recent meter readings from the wind plants, this can also give more frequent and accurate predictions. Third, a probabilistic approach to wind ramp forecasting can be used to better represent the likelihood of such events, and also account for the timing error of the Day-Ahead forecast. Lastly, many state-of-the-art forecasting applications have the capability to 
produce a prediction of the amount of variability in the wind along with the predicted value itself (e.g., a comparison of the $50 \%$ value vs. an $80 \%$ value can do this). This information can let the operator know an hour ahead of time if he needs to have enough load following or regulation reserve flexibility in case the wind does start varying away from its average value. Research targeted at giving operators a better idea of variability inside a time period, as well as error probability, is ongoing.

\section{Large Wind Ramps}

The February 26, 2008 drop in wind generation was large but relatively slow for a power system reliability event, taking three hours to drop 1,500 MW. This is typical for large wind events. A similar 1,500 MW drop in wind generation occurred a little over a year earlier, on February 24, 2007, and took two hours. The geographic diversity inherent as larger amounts of wind generation are added to the power system limit the speed that wind events can propagate across the wind generation fleet. "Analysis of West Texas Wind Plant Ramp-up and Ramp-down Events" (AWS Truewind, January 28, 2008) reports that ERCOT can expect less than one 2,800-MW, 30-minute drop in wind output (93 MW/minute) per year with a 15,000-MW wind fleet. Two to four 1,300-MW, 30minute increases or decreases can be expected (43 MW/minute). Large ramp events are limited even with very large amounts of wind generation and are still in the same size range with normal load movements.

Large wind ramps (Figure 4) are not comparable as reliability events with instantaneous generation failures. Conventional generation contingencies require dedicated spinning reserves and immediate response (2300 MW of ERCOT Responsive Reserve Service). Multi-hour wind ramps give the system operator time to utilize market responses, load response, supplemental reserves, or non-spinning reserves. All of these options are much cheaper than maintaining and deploying spinning reserves required for conventional generation.

\section{Load Response}

The fact that ERCOT used $1200 \mathrm{MW}$ of LaaR on February 26, 2008 as part of its event response is not unusual. ERCOT is very advanced and makes greater use of voluntary load response than any other region in the country. This benefits the power system and the responsive load. Loads compete to sell this service to ERCOT. ERCOT used responsive load as non-spinning reserve (30-minute response) 63 times in 2007 alone. The average load response was $1137 \mathrm{MW}$ and lasted just under three and a half hours. The largest deployment was $1354 \mathrm{MW}$ and the longest lasted six hours and 45 minutes. LaaRs provide spinning reserve (10-minute response) about ten times per year. The February 26, 2008 use of responsive load was neither exceptionally large nor exceptionally long (see http://www.ercot.com/mktinfo/services/nsd/archive.html).

\section{Summary of Lessons Learned}

There were a number of different measures that collectively led to the EECP event in ERCOT. In comparing the two load forecasts used for this day, it can be seen that there may be a need for an alternative load forecast methodology for days when the historical data inputs do not align with the present day. Using a load profile from a similar historical day instead of the most recent day may give some better predictions. The use 
and application of wind forecasts is also a good lesson here. In particular, utilities and RTOs need to evaluate the best way to predict wind ramp events, and based on the event, determine the different ways to adjust the system (including allowing for timing errors). It is important to note that wind ramps of this duration are very different than contingency events involving instantaneous loss of generation or transmission. Lastly, it is important to understand and recognize the considerable benefits of using interruptible load as a resource for system reliability in these types of situations. 


\section{REPORT DOCUMENTATION PAGE}

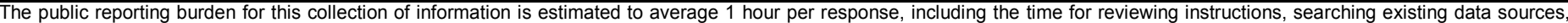

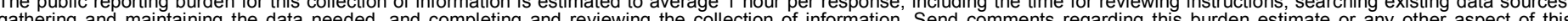

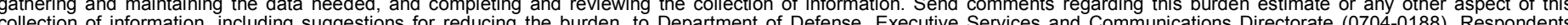

should be aware that notwithstanding any other provision of law, no

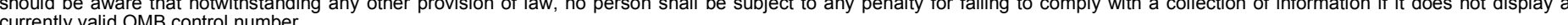

PLEASE DO NOT RETURN YOUR FORM TO THE ABOVE ORGANIZATION.

\begin{tabular}{l|l|l|l} 
1. REPORT DATE $(D D-M M-Y Y Y Y)$ & 2. REPORT TYPE & 3. DATES COVERED (FrOm - TO)
\end{tabular}

July 2008

Technical Report

4. TITLE AND SUBTITLE

ERCOT Event on February 26, 2008: Lessons Learned

5a. CONTRACT NUMBER

DE-AC36-99-G010337

5b. GRANT NUMBER

5c. PROGRAM ELEMENT NUMBER

6. AUTHOR(S)

E. Ela and B. Kirby.

5d. PROJECT NUMBER

NREL/TP-500-43373

5e. TASK NUMBER

WER8.5001

5f. WORK UNIT NUMBER

7. PERFORMING ORGANIZATION NAME(S) AND ADDRESS(ES)

National Renewable Energy Laboratory

1617 Cole Blvd.

Golden, CO 80401-3393

9. SPONSORING/MONITORING AGENCY NAME(S) AND ADDRESS(ES)

10. SPONSOR/MONITOR'S ACRONYM(S)

NREL

11. SPONSORING/MONITORING AGENCY REPORT NUMBER

12. DISTRIBUTION AVAILABILITY STATEMENT

National Technical Information Service

U.S. Department of Commerce

5285 Port Royal Road

Springfield, VA 22161

13. SUPPLEMENTARY NOTES

14. ABSTRACT (Maximum 200 Words)

The event analyzed in this paper is of special interest, and was widely reported on in the press, because wind generation played a partial role in the event.

15. SUBJECT TERMS

Wind energy; utilities; ERCOT; system integration; Texas; wind power; wind integration.

16. SECURITY CLASSIFICATION OF:
\begin{tabular}{|l|l|l|}
\hline $\begin{array}{l}\text { a. REPORT } \\
\text { Unclassified }\end{array}$ & $\begin{array}{c}\text { b. ABSTRACT } \\
\text { Unclassified }\end{array}$ & $\begin{array}{c}\text { c. THIS PAGE } \\
\text { Unclassified }\end{array}$ \\
\hline
\end{tabular}

\begin{tabular}{l|l|}
$\begin{array}{l}\text { 17. LIMITATION } \\
\text { OF ABSTRACT }\end{array}$ & $\begin{array}{l}\text { 18. } \\
\text { NUMBER } \\
\text { OF PAGES }\end{array}$ \\
UL & \\
\end{tabular}

19a. NAME OF RESPONSIBLE PERSON

19b. TELEPHONE NUMBER (Include area code) 